University of Nebraska - Lincoln

DigitalCommons@University of Nebraska - Lincoln

Faculty Publications: Department of Teaching, Department of Teaching, Learning and Teacher Learning and Teacher Education

Education

2004

Reexamining the Role of Cognitive Conflict in Science Concept

Learning

Sukjin Kang

Lawrence C. Scharmann

Taehee Noh

Follow this and additional works at: https://digitalcommons.unl.edu/teachlearnfacpub

Part of the Curriculum and Instruction Commons, and the Teacher Education and Professional

Development Commons

This Article is brought to you for free and open access by the Department of Teaching, Learning and Teacher Education at DigitalCommons@University of Nebraska - Lincoln. It has been accepted for inclusion in Faculty Publications: Department of Teaching, Learning and Teacher Education by an authorized administrator of DigitalCommons@University of Nebraska - Lincoln. 


\title{
Reexamining the Role of Cognitive Conflict in Science Concept Learning
}

\author{
Sukjin Kang, ${ }^{1}$ Lawrence C. Scharmann, ${ }^{2}$ and Taehee Noh ${ }^{3}$ \\ 1 Jeonju National University of Education, Korea \\ 2 Kansas State University, USA \\ 3 Seoul National University, Korea \\ Corresponding autor - Sukjin Kang, Department of Science Education, \\ Jeonju National University of Education, Jeonju, 560-757, Korea; \\ email: kangsj@jnue.ac.kr
}

\begin{abstract}
In this study, we defined and quantified the degree of cognitive conflict induced by a discrepant event from a cognitive perspective. Based on the scheme developed, we investigated the relationship between cognitive conflict and conceptual change, and the influences of students' cognitive characteristics on conflict in learning the concept of density. Subjects were 171 seventh-grade girls from two city middle schools in Korea. Tests regarding logical thinking ability, field dependence/independence, and meaningful learning approach were administered. A preconception test and a test of responses to a discrepant event were also administered. Computer-assisted instruction was then provided to students as a conceptual change intervention. A conception test was administered as a posttest. In analyzing students' responses to the discrepant event, seven types of responses were identified: Rejection, reinterpretation, exclusion, uncertainty, peripheral belief change, belief decrease, and belief change. These types were then ordered into four levels. The results indicated that there existed a significant correlation between cognitive conflict and conceptual change. $t$-test results revealed that there were statistically significant differences in the degree of cognitive conflict by the levels of students' logical thinking ability and field dependence/independence. Meaningful learning approach, however, was found to have no statistically significant effect on cognitive conflict. Educational implications are discussed.
\end{abstract}

Keywords: cognitive conflict, discrepant event, science concept learning

Published in Research in Science Education 34 (2004), pp 71-96.

Copyright (C) 2004 Kluwer Academic Publishers. Used by permission 
Over the last twenty years, research on students' conceptual understanding in science has been quite active. The importance of students' preinstructional or alternative conceptions was a common theme running through this area of research (Scott, Asoko, \& Driver, 1992), and numerous researchers continue to investigate students' conceptions in various content domains (e.g., Borges \& Gilbert, 1999; Roald \& Mikalsen, 2000; Teixeira, 2000; Tytler, 2000; Voska \& Heikkinen, 2000). Previous research pointed out that many students' preconceptions, if not all, are often both pervasive and resistant to change through traditional expository forms of instruction, and simply informing students of scientific conceptions is not enough. According to the alternative conception paradigm(e.g.,Driver, 1994), students' preconceptions are impervious to change because their preconceptions are not merely mistakes or false beliefs but instead, students possess their own cognitive support groups and defense mechanisms (Strike \& Posner, 1992). Based on this viewpoint, several learning models were proposed (e.g., conceptual change model, generative learning model, etc.). Among them, the conceptual change model has been often applied to situations in which the target learning outcome is to change students' misconceptions.

The conceptual change model describes learning as the interaction that takes place between a student's experience and his/her current conception. Therefore, many studies on conceptual change have focused on establishing conditions that promote situations where the student's existing conception can be made explicit and then is directly challenged to create a state of conflict. As a result, many conceptual change models incorporate specifically designed strategies called cognitive conflict approaches (Chan, Burtis, \& Bereiter, 1997). Based on the theoretical model described by Posner, Strike, Hewson, and Gertzog (1982), this approach generally involves identifying a student's current state of knowledge and bringing about conflict so that he/she can replace the preconception with a scientifically accepted conception.

The concept of cognitive conflict has its origin in Piaget's theory of equilibration. The need to reduce conflict is a powerful human motivation. Therefore, many Piagetian advocates believe that experiencing conflict is indispensable to learning. The concept of cognitive conflict also has had much influence on science education researchers, 
especially those who work in the area of concept learning. Some of these researchers regard cognitive conflict as a necessary condition for conceptual change in learning science concepts. Although the $\operatorname{cog}$ nitive conflict approach is one of the most frequently investigated strategies and consistently shows significant effects (Guzzetti, Snyder, Glass, \& Gamas, 1993), some researchers have raised questions about the role of cognitive conflict. Zimmerman and Blom (1983) investigated whether cognitive conflict is a precondition to acquire conservation of weight. They were not able to find any evidence, however, supporting the necessity of cognitive conflict. They sarcastically concluded that "Although there is extensive evidence that (cognitive) conflict has been a useful condition in the minds of theorists to explain learning, there is little evidence that (cognitive) conflict is widely experienced in the minds of learners." (parentheses added by present authors). Other science education researchers (Dreyfus, Jungwirth, \& Eliovitch, 1990; Linn, 1986; Tsai, 2000; Vosniadou, 1999) also pointed out that students are often unable to achieve meaningful conflict or to become dissatisfied with their preconceptions, even when confronted with conditions involving conflict. Moreover, even if the conflict is highlighted by some means, there is no guarantee that students will accept either its existence or its significance (Scott et al., 1992).

Is it a merely false belief that cognitive conflict is a necessary condition for conceptual change? Previous research that has investigated the effect of the cognitive conflict approach in science education, however, has consistently reported positive results. How can we accept these disparate views on cognitive conflict? One reason for this inconsistency might be that there are different interpretations of cognitive conflict. Science education researchers have examined the effects of cognitive conflict mainly on the bases of comparisons of group differences, and they tended to implement a combination of strategies and then evaluate their total impact (Guzzetti et al., 1993). In addition, cognitive conflict is often described briefly or not at all (Gorsky\& Finegold, 1994). As a result, it is not easy to grasp the explicit meaning of cognitive conflict in science education research. Therefore, the definition of cognitive conflict should be more explicit and more specific in order to investigate the role of cognitive conflict in producing conceptual change. 


\section{Cognitive Conflict and Discrepant Event}

Berlyne (1970) described cognitive conflict as "a condition in which mutually interfering processes occur simultaneously and in which selection of a motor response from a set of competing alternatives is therefore hampered" (p. 968). Unlike previous ones, his definition gave cognitive conflict a kind of generality such that the significance of cognitive conflict was seriously taken into consideration in a wide variety of learning situations (Cantor, 1983). The concept of cognitive conflict was more specifically explained by Hewson (1988), and Stavy and Berkovitz (1980). They identified that there are two kinds of cognitive conflict related to the different forms of equilibration in Piaget's theory; the conflict between a student's conception and the experience, and the conflict between two different cognitive structures related to the same phenomenon. Of these two kinds of conflict, we will focus on the former because it is a key construct involved in phenomena known as discrepant events. Discrepant events have been one of the most important components in science education research based on the cognitive conflict approach, because dissatisfaction with an existing conception is central to the process of conceptual change and a discrepant event is the major source of initial dissatisfaction (Posner et al., 1982).

Generally, a discrepant event is the physical experience that provides students with novel evidence to contradict their existing conceptions. The instructional use of a discrepant event assumes that it could induce cognitive conflict. When students encounter a discrepant event, it is expected that they should discover that their preconceptions are inadequate to explain the new experience, which might lead them to consider or invent alternative conceptions that can account for the discrepant event. However, it has been reported that students in many cases do not necessarily arouse cognitive conflict through merely experiencing a discrepant event (e.g., Chinn \& Brewer, 1998; Gorsky \& Finegold, 1994; Mason, 2001; Shepardson \& Moje, 1999; Tirosh, Stavy, \& Cohen, 1998). According to Murray (1983), even if the contradictory event was presented to students, it may be (a) simply unnoticed, (b) tolerated or explained as paradox, mystery, or magic, (c) seen as an independent event, or (d) resolved prematurely or trivially by the discard of conflicting elements. 
Perhaps, a simple falsification view of science has had too much influence on the research grouped under the cognitive conflict approach. At the same time, however, it is also unreasonable to simply underestimate or disregard the role of a discrepant event, because there have been only a few studies in which a separate corroborative measure of cognitive conflict was collected. Thus, the relationship between a discrepant event and conceptual change needs to be more fully clarified.

Zimmerman and Blom (1983) tried to operationalize cognitive conflict induced when preoperational first graders were presented with videotapes of varying degrees of conflict regarding conservation problems. They used two kinds of measures in quantifying cognitive conflict. First, based on Smedslund's (1961) operational definition of cognitive conflict, they chose students' hesitation or latency in rendering judgments to items asked during an individual interview, as one indicator of conflict. Their second index of conflict was the students' selfreport, 3-point rating of feelings of uncertainty-certainty toward their responses to given items. More recently, Vandenplas-Holper (1996) measured cognitive conflict with 5 to 7-year-old children working on conservation tasks in triads. He used the sum of three markers as the degree of cognitive conflict: (a) spontaneous intra-individual conflict that occurs when the children disagree among themselves by using marked indicators of disagreement within the same time interval or within two adjacent intervals, (b) the number of experimenter's statements that stress intra- or inter-individual conflict, and (c) the number of children's surprises with such interjections as "ah" or "oh." In a study investigating students' responses to specific information that contradicted their naive conceptions regarding evolution, Chan et al. (1997) measured students' belief change by asking students to indicate on an 11-point scale whether they agreed or disagreed with given statements. Two experts also evaluated each student's response using the protocols of the interview. A criterion measure was then constructed to represent the average rating of the protocols. Correlations between students' ratings and the criterion measures were computed and used as the degree of belief change.

To sum up, investigators attempting to quantify cognitive conflict generally have measured either students' overt behaviors or students' ratings of given statements or problems. It seems apparent that student's overt behavior like hesitation, surprise, or talking to oneself 
could be one of the hallmarks of cognitive conflict (Cantor, 1983). On the contrary, conflict could be only one of many possible reasons for those behaviors. Furthermore, the relationship between students' overt behaviors (i.e., hesitation, etc.) and cognitive conflict is not so direct as to regard the scores obtained from the observation of students' behaviors as the degree of cognitive conflict. The style and/or intensity of behavior expressing his/her conflict must vary from student to student so that we should never overlook the influence of the student's personality on that relationship. The other index, the self-report of belief, also should be seriously questioned. The problem here is that the score obtained from a self-report does not equal the degree of cognitive conflict induced but instead the degree of a student's subjective feeling about the given experience. Therefore, a more direct indicator that can detect psychological vacillations is needed in order to enhance the validity of measuring cognitive conflict.

In this study, therefore, we sought to examine the relationship between cognitive conflict induced by a discrepant event and conceptual change. To this end, we devised a scheme for measuring cognitive conflict from students' responses to a discrepant event. Based on this scheme, then, we explore the relationship between cognitive conflict and conceptual change.

We also investigate the influences of students' cognitive characteristics on the type of responses to discrepant events and the cognitive conflict it arouses. The success of using discrepant events in conceptual change learning probably depends on the willingness and ability of students to recognize the overt conflict. Thus, it could be assumed that students' cognitive characteristics might be crucial factors when teachers use discrepant events to initiate cognitive conflict. Based on a synthesis of the research evidence cited in the relevant literature, we investigate the influences of three cognitive variables which deserve special attention: logical thinking ability, field dependence/independence, and learning approach.

In order to reach a state of cognitive conflict, students need to determine whether discrepant events are or are not valid and whether discrepant events are or are not congruent with their existing conceptions (Chinn \& Brewer, 1993). Thus, students who cannot effectively use logical hypothetic-deductive reasoning (Lawson \& Thompson, 1988) might fail to exhibit cognitive conflict in response to a discrepant event. Field dependence/independence, which is related to 
an individual's cognitive style concerning how successfully he/she can disembed relevant information from a complex and potentially confusing background (Witkin, Moore, Goodenough, \& Cos, 1977), might be also a factor that influences cognitive conflict. Finally, students' learning approaches might also influence cognitive conflict - whether students accept the conflicting evidence and accommodate their existing conceptions or whether they use various coping tactics to avoid conflict. Because, as Donn (1989) reported, students classified as using a meaningful learning strategy tended to respond to novel problems by self-questioning and by relating and elaborating ideas, whereas their counterparts tended to respond by stating definitions and by failing to elaborate upon their ideas.

\section{Methods}

\section{Target Misconception}

On choosing a concept to use in this study, several criteria were considered. First, we needed a concept that has been reported as difficult for students to learn through traditional expository instruction. Second, the concept should have been documented as one about which many students have a similar misconception. Third, the concept should be intelligible to students. Finally, the concept should be one for which a discrepant event exists to confront the misconception. The concept satisfying our criteria was density. Many researchers and educators have reported that density is a difficult concept to teach (e.g., Rieck, 1994; Shepherd \& Renner, 1982), and traditional approaches to teaching density have had limited success at best at promoting a scientifically accepted conception (Hewson \& Hewson, 1983; Rowell \& Dawson, 1977). One of the inherent difficulties with the concept of density, unfortunately, is that there is no direct way of measuring it. Some investigators have pointed out the complexity of the concept. That is, the concept of density is difficult because it requires an understanding of ratio and proportion (Rowell \& Dawson, 1977) or because it is a compound variable dealing with two simultaneous variables, mass and volume (Adey \& Shayer, 1988). The result that even older students had difficulties in understanding density (Hewson, 1986), however, means that there might be another factor 
to consider. According to Smith, Snir, and Grosslight (1992), students generally have alternative conceptual frameworks for matter so that developing a concept of density should require a restructuring of their frameworks.

An undifferentiated weight-density concept is one of the most prevailing misconceptions among middle school students (Hewson \& Hewson, 1983;Noh, Kang, Kim, Chae, \& Noh, 1997; Rowell \& Dawson, 1977; Smith, Carey, \& Wiser, 1985). Students fail to distinguish between weight and density. Instead, they unite components from both concepts in one undifferentiated weight-density concept (Smith et al., 1985) because mass, volume, and weight are correlated in everyday life (Klopfer, Champagne, \& Chaiklin, 1992). As a result, students usually use a poorly differentiated concept like "amount" instead of weight or density (Noh et al., 1997). Some researchers (e.g., Noh et al., 1997; Smith et al., 1992), nonetheless, have demonstrated that appropriate conceptual change instruction can lead some 7 th graders to understand the concept of density. Finally, a list of observable discrepant events that contradict the misconception is also available. Since the undifferentiated weight density concept satisfied all our criteria, we chose it as the target misconception of this study.

\section{Participants}

This study was carried out with 350 grade 7 students (13 or 14 years old) in Korea. According to the National Science Curriculum of Korea, the concept of density should be taught at grade 8 . Therefore, none of the students had been formally taught the density concept. All participants were girls and were selected from two city middle schools. We needed schools that possessed a multimedia center equipped with enough personal computers (i.e., at least one computer for each student) in order to conduct our research. However, it is not so easy to arrange to use schools satisfying this condition because, in Korea, the average number of students per class is still about 35 so that most instruction using computers generally proceeds in pairs. Moreover, though many middle schools have been changed to reflect a coeducational status, there are still many boys' and girls' schools in Korea. Because of the difficulties for arranging schools and necessity of having students work independently on a personal computer, we were obliged to select two girls' schools. 
While conceptual change models have been widely advocated for helping students deal with misconceptions, little research has examined the relation between conceptual change and gender (Chambers \& Andre, 1997). Though it has been often reported that there is a science achievement difference between boys and girls, a major review of gender and science education indicated that the differences decrease to a trivial level among younger students (Kahle \& Meece, 1994). Chambers and Andre (1997) also reported that, when students' interest level, experience, and prior knowledge had been controlled, there was no significant difference by gender in learning direct current concepts through the conceptual change approach. Thus, although the potential for a gender difference might exist, we did not perceive it to be a likely threat to the validity of our research results.

\section{Instruments}

Preconception test

For the purposes of this study, there was a need to exclude students who did not exhibit the target misconception. We developed a preconception test designed as a tool for choosing appropriate subjects and piloted it twice. In this test, students were asked to answer the question - "When two balls of the same size were dropped into the water, a small black ball weighing $100 \mathrm{~g}$ floated whereas a small gray ball weighing $500 \mathrm{~g}$ sank. Here is a 1,000 g large black ball made of same material as the small black ball. Does it sink or float when it is dropped into the water?" - and to explain reasons for their answers.

Test of responses to a discrepant event

A Test of Responses to a Discrepant Event (TRDE) was developed to examine the ways in which students respond to a discrepant event. This test was a modification of an instrument that Chinn and Brewer (1998) used. They used four different initial theories and six different pieces of anomalous data to increase the diversity of students' responses. Our purpose, however, was to investigate the influences of a given discrepant event on conceptual change in science instruction. Thus, we presented all students with only one initial theory and one discrepant event in the TRDE, because teachers generally present 
their students with a single discrepant event with the intent to contradict the most widely held misconception(s). The TRDE was also pilot-tested twice in order to verify students' comprehension of it. The TRDE consists of the following three parts: Initial explanation, discrepant event, and students' rating. Each part is elaborated upon in the next three paragraphs.

Initial explanation: Students read a text in which a man suggesting that the large black ball weighing 1 ,ooo $g$ must sink because it is much heavier than the gray ball which also sank. In order to support this explanation, some evidentiary examples were also presented here (e.g., "A piece of stone or iron sinks because it is heavy, but a block of wood or Styrofoam floats because it is light."). We expected that students who had the target misconception would enhance the credibility of their ideas after reading this text. As a check of initial belief, students were asked to write whether they believed this initial explanation or not, immediately after they had read it.

Discrepant event: After reading the text which supported their initial beliefs, students read another text concerning a discrepant event which contradicted the initial explanation. An experimental result of a middle school student was described in the text. "Actually, a $100 \mathrm{~g}$ small plastic ball floated whereas a $500 \mathrm{~g}$ small iron ball sank in the water. However, a 1,00o g large plastic ball also floated contrary to the initial explanation." To reduce students' doubt about the reliability of the experimental result, it was emphasized that other students in the class obtained the same results. In comparing their initial beliefs with the given discrepant event, we expected to evoke conflict in students holding the misconception.

Students' rating: In this part, students evaluated both the discrepant event and the initial explanation. First, students rated the believability of the discrepant event (i.e., chose one from "I believe," "I do not believe," and "I do not know") and produced reasons for their ratings. Second, students rated the extent of consistency between the discrepant event and the initial explanation (i.e., chose one from "consistent," "inconsistent," and "I do not know"). They also gave written explanations for their ratings. Finally, students reported whether their belief had changed after having read the discrepant event, and explained their reasons. 


\section{Conception test}

We developed a conception test to examine whether the target misconception changed to the scientific conception. Several test items were constructed on the basis of previous research concerning students' misconceptions about density (Adey \& Shayer, 1988; Klopfer et al., 1992; Noh et al., 1997). Two rounds of pilot tests were conducted on 8th-grade Korean middle school students to eliminate or modify inappropriate items. The final version of the conception test consisted of four items. All conception test items were written in a multiple-choice format. Each item contained, in addition, an accompanying open-ended section to collect information about students' rationales for their choices. The face validity of the test was verified by a panel of experts consisting of three science educators and three middle school teachers. The Cronbach's internal consistency reliability coefficient for this test was .73. A 3-point scale was developed to rate the conception test. No and irrelevant responses were rated as a "o," responses indicating partial understanding (i.e., rationales were incomplete even though the correct option was chosen) were rated as a "1," and responses showing sound understanding were rated as a "2." Two raters independently scored a subset of randomly selected students' answers. Each disagreement was discussed by the raters and then resolved. After 90\% interrater agreement was obtained, one rater scored all the answers and the other independently checked the scoring.

\section{Tests of cognitive variables}

Three tests were administered to measure students' cognitive characteristics in this study. All three tests were translated into Korean from English. The translation was verified by three science educators. Furthermore, we interviewed several students during pilot studies to verify whether students correctly understood the meanings of items. All of these students were, in science, of below average achievement level. Only a few minor problems were detected in responses from students and the inappropriate wordings of items were revised with the help of middle school teachers.

Students' logical thinking ability was measured with the short-version Group Assessment of Logical Thinking (GALT; Roadrangka, Yeany, 
\& Padilla, 1983) which includes 2 items each for the following 6 types of reasoning: Conservation, proportional reasoning, controlling variables, probabilistic reasoning, correlational reasoning, and combinational reasoning. The total scores range from o to 12 . The Cronbach's internal consistency reliability coefficient for the sample used in this study was determined as .70 .

Field dependence/independence was assessed by the Find-A-Shape Puzzle (FASP; Linn \& Kyllonen, 1981). This test measures students' ability to disembed relevant information from an irrelevant background. Linn and Kyllonen showed that the FASP loads on the same factor as previously validated field dependence/independence instruments. In this test, students must find simple figures concealed in five complex ones in a given time limit. One point is awarded for correctly locating each simple figure; the total scores range from o to 20 . The internal consistency reliability coefficient was .89 for the scores obtained in this study.

Previous research revealed that students have predisposed learning orientations (Cavallo, 1996; Cavallo \& Schafer, 1994; Entwistle \& Ramsden, 1983). In order to identify their learning orientations, students were given a Meaningful Learning Approach Questionnaire (MLAQ) selected from the Revised Approaches to Studying Inventory (RASI; Entwistle \& Tait, 1994) designed to assess students' approaches to learning. The RASI consists of five subcategories: Deep approach, surface approach, strategic approach, lack of direction, and academic self-confidence orientations. Since item separability of the deep, surface, and strategic approach subcategories had been validated (Duff, 1997), we used 10 questions that addressed students' deep (meaningful) learning approaches in this study. The instrument asked students to respond to questions regarding how they learn, ranging from 1 (disagree) to 5 (agree). An internal consistency reliability coefficient of .81 was obtained for this test.

\section{Procedure}

To investigate their cognitive characteristics, students were administered the GALT, the FASP, and the MLAQ. Next, the preconception test for identifying students in possession of the target misconception and the TRDE for examining their responses to a discrepant event were conducted. Finally, after completing all pretests, students 
were exposed to 15 minutes of conceptual change intervention concerning the concept of density. In order to control the influences of teacher and learning environment on students' learning, we developed a computer program using the Macromedia Flash 5 that has advantages in creating animations and presentations. Computer assisted instruction (CAI) using this program was implemented as the intervention. Students were assigned to work individually on the CAI program to exclude the possibility that interpersonal interactions might influence their individual learning.

The CAI program was devised to correspond to the concept introduction and application stages of general conceptual change models. Through the CAI program, students were first presented with animation showing that weight cannot be a criterion for predicting whether a certain object would sink or float. The new concept, density which was defined as the mass per unit volume, was then introduced as an alternative criterion for predicting a "sink or float" problem. At the end of the CAI program, students were provided with some application problems and received feedback when it was necessary.

On designing the content of the CAI program, in addition, we decided to concentrate on explaining the phenomenon, a "sink or float" problem, at a macroscopic level because the microscopic view of matter is not necessary to achieve an understanding of the distinction between weight and density. Scientists had also achieved a clear differentiation between weight and density even before their acceptance of an atomic theory of matter in the history of science (Smith et al., 1985).No attempt was made to teach students the distinction between weight and mass because the numeric value of the two quantities is proportional on the Earth and this distinction is not requirement for seventh graders to understand the core concept of density. Students completed the conception test the day after the instructional protocol.

From an original pool of 350 students, we included 171 subjects in this study. First, 130 students were excluded because their answers to the preconception test indicated that they did not possess the target misconception. Another 27 students were eliminated because they did not agree with the initial explanation. Although these students also had chosen the wrong option in the preconception test as had the subjects, we regarded their disagreement with the given initial explanation as indicating a possibility that they had other misconceptions. Finally, 22 students were ineligible because they did not complete all tests. 


\section{Cognitive Conflict Scoring Protocol}

Unlike previous research which focused on either students' behaviors as expressions of conflict or students' self-ratings, we wanted a more direct method of quantifying cognitive conflict. The extent of cognitive conflict induced by a discrepant event appears to be a function of the interaction between a student's existing conception and his/her new experience. The greater the difficulty in reconciling an existing conception and a discrepant event, the greater the conflict. For example, if students were able to cope with a discrepant event by making relatively minor changes to their existing conceptions, then it would lead to a low state of cognitive conflict. Moreover, when they are working on the process of assimilation, a limited restructuring of an existing conception, students typically show certain responses like adjusting or distorting the experience to conform to their existing conceptions (Tsai, 2000). Therefore, responses to a discrepant event might be one of the indicators for quantifying cognitive conflict.

It has been reported that students make a diverse range of responses to discrepant events (Chinn \& Brewer, 1993, 1998; Gorsky\& Finegold, 1994; Mason, 2001; Shepardson \& Moje, 1999; Tirosh et al., 1998). Gorsky and Finegold (1994) investigated students' responses to an anomaly regarding "forces." They asked nine high school students to set up a force array showing the forces he/she claims are acting on an object and then presented each of them with a simulation of the resulting behavior of the system. They hypothesized that cognitive conflict might be generated when the simulated behavior is clearly incompatible with a student's expectation (i.e., based on their real-world experience). They analyzed students' verbal responses as students learned with the simulation and classified these responses into several types according to the extent of the conflict generated: despair, rejection, skepticism, and curiosity. Chinn and Brewer (1998) also reported several ways in which students respond to anomalous data: (a) ignoring the data; (b) rejecting the data; (c) professing uncertainty about the validity of the data; (d) excluding the data; (e) holding the data in abeyance; (f) reinterpreting the data; (g) accepting the data and making peripheral theory change; and (h), accepting the data and changing their theory. In their studies, Chinn and Brewer proposed more specific criteria for the exploration of students' 
responses to discrepant events: Believability of a discrepant event, inconsistency between a discrepant event and students' existing conceptions, and belief change after experiencing a discrepant event. These criteria have the merit of dealing with conflict directly from a cognitive perspective.

In this study, first, we classified students' responses to a discrepant event into the following seven types:

1. Rejection: Denying the validity of the discrepant event,

2. Reinterpretation: Interpreting the discrepant event differently within the frameworks of their existing conceptions,

3. Exclusion: Considering the discrepant event as irrelevant to their existing conceptions,

4. Uncertainty: Being confident in neither the discrepant event nor their existing conceptions,

5. Peripheral belief change: Accepting the discrepant event by making minor changes to their existing conceptions,

6. Belief decrease: Feeling dissatisfaction with their existing conceptions but not being confident of their decisions,

7. Belief change: Feeling dissatisfaction with their existing conceptions and completely giving them up.

The classifications were based on the students' written responses in the TRDE, which possesses three questions that are consistent with the three requisite criteria proposed by Chinn and Brewer (1998). Two raters independently classified a subset of randomly selected responses. Discrepancies between the raters were then discussed and resolved. This discussion/resolution procedure was repeated until the intercoder agreement reached 90\%. Then, one rater classified all the responses again while the other rater independently checked the classification.

According to Posner et al. (1982), cognitive conflict is generated when students feel dissatisfaction with their existing conceptions. Thus, for the purposes of this study, we operationalized cognitive conflict as the degree of dissatisfaction a student exhibits with his/her existing conception after being presented with a discrepant event. Limón and Carretero (1997) also suggested that there are different types of responses to a discrepant event that could be ordered in a continuum from the least acceptance of the discrepant event to the most acceptance of it. Of the seven types, rejection, reinterpretation, 
and exclusion are reported to produce no change in students' beliefs in their existing conceptions (Chinn \& Brewer, 1993; Gorsky \& Finegold, 1994) so that these responses were rated as a "o." Uncertainty is a response type that indicates no confidence in the validity of a discrepant event as well as an existing conception; such responses were rated as a "1." Responses classified into peripheral belief change and belief decrease indicate dissatisfaction with an existing conception, at least to some extent, and were rated as a " 2 ." Belief change, a function of entire dissatisfaction with an existing conception, was rated as a " 3 ."

\section{Results}

\section{Students' Responses to the Discrepant Event}

Seven types of responses were found in the analyses of students' responses to the discrepant event: rejection, reinterpretation, exclusion, uncertainty, peripheral belief change, belief decrease, and belief change (Table $\mathbf{1}$ ).

Thirty-two students (18.7\%) rejected the discrepant event. They did not believe the discrepant event although they were aware of the inconsistency between the discrepant event and their existing conceptions. With rejection, there was no belief change. Rejection was the most common response type among students who decided not to change their existing conceptions in our study. Over 70 percent of

Table 1. Frequencies (and Percentage) of Responses to the Discrepant Event.

\begin{tabular}{lcc} 
Type of responses & This study & Chinn \& Brewer (1998) \\
\hline Ignoring & - & $15(8.2)$ \\
Rejection & $32(18.7)$ & $61(33.5)$ \\
Reinterpretation & $7(4.1)$ & $43(23.6)$ \\
Exclusion & $11(6.4)$ & $4(2.2)$ \\
Abeyance & - & $17(9.3)$ \\
Uncertainty & $13(7.6)$ & $31(17.0)$ \\
Peripheral belief change & $17(9.9)$ & $3(1.6)$ \\
Belief decrease & $24(14.0)$ & - \\
Belief change & $67(39.2)$ & $8(4.4)$ \\
Total & $171(100 *)$ & $182(100 *)$ \\
\hline
\end{tabular}

* Differences from $100 \%$ due to recording errors. 
these students (23 out of 32) seemed not to be able to accept the result of the discrepant event probably because their initial beliefs were just too strong: "How could the lighter object float? It's impossible." or "The heavy object should sink, and the light object should float. It's so natural." Whereas six students raised more specific questions regarding the validity of the experiment: "Why did the student use two kinds of balls (i.e., plastic and iron) in his experiment? He should have used only one kind of ball." (parenthesis added by present authors) or "If the plastic ball weighed $1 \mathrm{~kg}$, it's too bulky to be dropped into the water tank."

Seven students (4.1\%) distorted the discrepant event and regarded it as consistent with their beliefs. As a result, no change was made in their existing conceptions. Most of these students (5 out of 7) had a concept of heaviness that held two different meanings. For example, one of these students explained her reason as "I believe the result of the experiment because plastic is a light material by nature. So, the plastic ball could float though it is heavier than the iron ball which sank." It is apparent that these students used the term heavy or light for two entirely different meanings; one as the weight and the other as the property of the material. It should be also noted here that a few students, who rejected the discrepant event, also tended to be confused in using appropriate terms, but this tendency had little influence on their responses to the discrepant event. For the students who reinterpreted the discrepant event, however, the dual meaning of heaviness had a marked impact on their reactions to the discrepant event.

Eleven students (6.4\%) excluded the discrepant event. They believed the result of the discrepant event and agreed that it was not consistent with their existing conceptions. However, there was no belief change because the discrepant event was taken as having no direct connection with their existing conceptions or merely a kind of exception. Most of them (10 out of 11) were found to have a dual meaning for the heaviness concept like those classified as being the "reinterpretation" type. It was so natural to them that the plastic ball, which weighs more than the iron ball, floated because plastic is a light material by nature. Therefore, there is no reason for them to change their existing conceptions.

Thirteen students (7.6\%) responded that they could not decide whether they should give up their existing conceptions or not. Unlike 
other response types, responses to the three criteria were highly diverse among students classified to this category; someone agreed to the believability and/or the inconsistency, but others did not. The only thing that individuals in this category had in common, is that their decisions were not settled yet. One student said, "After reading the result of the experiment, I don't know which one is right."

Seventeen students (9.9\%) accepted the discrepant event by making some modifications to their existing conceptions. Eleven of them were also found to possess a dual meaning for the heaviness concept. Unlike those students categorized as a "reinterpretation" or an "exclusion" type, however, they revamp their existing conceptions to some extent: "Heavy objects generally sink. But it's not always right. If the material is very light, even heavy objects could float." Five of them tended to revise their existing conceptions more systematically: "I found out my mistake. The kinds of material also affect the sinking or floating of objects. So, you must consider both the weight and the kind of material in predicting whether a certain object would sink or float."

Twenty-four students (14.0\%) believed the discrepant event and found out that the discrepant event was not consistent with their existing conceptions. As a result, they agreed that their existing conceptions had some problems. However, they hesitated to completely abandon them. Representative reasons for the decrease of conviction toward their existing conceptions, were the superiority of the experimental result ("I think the experimental result is more reliable than a simple opinion.") and the limitation of their existing conceptions in terms of explanatory power ("If the material is light like plastic, my initial thought is not right any longer.").

Belief change was the most frequent response type in this study. Sixty-seven students (39.2\%) showed clear signs of abandoning their existing conceptions. The major reason given by these students (28 out of 67) was the superiority of the experimental result over an opinion: "I gave up my initial thought because the experiment showed me clear evidence." Although no alternative concept was presented by the TRDE, 25 students indicated their own alternative explanations: "Whether a certain kind of object would sink or float is dependent on the material of that object." In some cases (3 students), the target misconception was replaced by another misconception: "It's not the weight but the volume that decides whether an object would sink or float." 
Table 2. Means and Standard Deviations of the Tests.

\begin{tabular}{lccccc} 
GALT & FASP & MLAQ & TRDE \\
$(n=170)$ & $(n=165)$ & $\begin{array}{c}\text { Conception test } \\
(n=167)\end{array}$ & $\begin{array}{c}(n=171) \\
(n=171)\end{array}$ \\
\hline Mean & 4.08 & 10.03 & 29.54 & 1.73 & 4.01 \\
SD & 2.44 & 5.06 & 5.88 & 1.25 & 2.56 \\
\hline
\end{tabular}

Table 3. Correlation Coefficients among Variables.

\begin{tabular}{lclll} 
Variable & GALT & FASP & MLAQ & \multicolumn{2}{l}{ TRDE } \\
\hline Logical thinking ability (GALT) & - & & \\
Field dependence/independence (FASP) & $.258^{* *}$ & - & & \\
Meaningful Learning approach (MLAQ) & $.224^{* *}$ & $.213^{* *}$ & - & \\
Cognitive conflict (TRDE) & $.154^{*}$ & $.240^{* *}$ & .033 & - \\
Conceptual change (Conception test) & $.511^{* *}$ & $.292^{* *}$ & $.195^{*}$ & $.232^{* *}$ \\
\hline
\end{tabular}

$\star p<.05$

$* * p<.01$

\section{Relationship between Cognitive Conflict and Conceptual Change}

Means and standard deviations of the tests administered are presented in Table 2. Pearson correlation coefficients among students' test scores are presented in Table $\mathbf{3}$. The correlation coefficient, between the TRDE scores and the conception test scores, was statistically significant $(p<.01)$. The scores of the GALT and the FASP showed statistically significant correlations with the score of the TRDE ( $p<$ .05 and $p<.01$, respectively). The scores of the GALT, the FASP, and the MLAQ were also significantly correlated statistically with the conception test scores.

\section{Types of Responses and the Degree of Cognitive Conflict by Cognitive Variables}

In order to investigate the effects of students' cognitive characteristics on the degree of cognitive conflict, we selected students from the top 25\% (high level) and from the bottom 25\% (low level) based on the scores of the GALT, the FASP, and the MLAQ respectively. Then, we compared the distributions of response types (Table 4) and the scores of the TRDE (Table 5) between the two groups. 
Table 4. Frequencies (and Percentage) of Students' Responses to the Discrepant Event by Levels of the Cognitive Variables.

\begin{tabular}{lllllll} 
Type of responses & $\begin{array}{l}\text { GALT } \\
\text { Low }\end{array}$ & High & $\begin{array}{l}\text { FASP } \\
\text { Low }\end{array}$ & High & Low & High \\
\hline Rejection & $5(22.7)$ & $4(12.1)$ & $11(31.4)$ & $8(20.5)$ & $10(27.0)$ & $7(17.5$ \\
Reinterpretation & $2(9.1)$ & - & $3(8.6)$ & - & - & $2(5.0)$ \\
Exclusion & $1(4.5)$ & $1(3.0)$ & $5(14.3)$ & $1(2.6)$ & $3(8.1)$ & $2(5.0)$ \\
Uncertainty & $2(9.1)$ & - & $3(8.6)$ & $5(12.8)$ & $3(8.1)$ & $2(5.0)$ \\
Perip. belief change & - & $8(24.2)$ & $3(8.6)$ & $5(12.8)$ & $4(10.8)$ & $5(12.5)$ \\
Belief decrease & $4(18.2)$ & $2(6.1)$ & $4(11.4)$ & $3(7.7)$ & $3(8.1)$ & $3(7.5)$ \\
Belief change & $8(36.4)$ & $18(54.5)$ & $6(17.1)$ & $17(43.6)$ & $14(37.8)$ & $19(47.5)$ \\
Total & 22 & 33 & 35 & 39 & 37 & 40 \\
\hline
\end{tabular}

Table 5. T -test Results on the Degree of Cognitive Conflict by the Levels of Cognitive Variables.

\begin{tabular}{lrrrrr} 
Variable & \multicolumn{2}{c}{ Mean (SD) } & $t$ & $d f$ & $p$ \\
\hline GALT & $1.55(1.34)$ & $2.24(1.06)$ & 2.150 & 53 & .036 \\
FASP & $1.00(1.21)$ & $1.85(1.23)$ & 2.980 & 72 & .004 \\
MLAQ & $1.59(1.32)$ & $1.88(1.28)$ & .94475 & .348 & \\
\hline
\end{tabular}

For students with high logical thinking ability there were more belief change responses whereas there were more rejection and reinterpretation responses for those with low logical thinking ability. A $t$-test result showed that the difference between the TRDE scores of these two groups was statistically significant $(p<.05)$. These results indicated that students with high logical thinking ability tended to accept the discrepant event and feel dissatisfaction with their existing conceptions whereas those with low logical thinking ability tended to respond in unexpected ways and to maintain their own existing conceptions. In the analyses of the effects of field dependence/independence on cognitive conflict, more obvious differences between the high and the low groups were found. Field independent students made more responses of belief change whereas field dependent students made more responses of rejection and reinterpretation. The differences between the TRDE scores of these two groups were also found to be statistically significant $(p<.01)$. That is, more cognitive conflict was aroused for the field independent students than for the field dependent students after experiencing 
the discrepant event. In the case of learning approach, more belief change responses were found for students with a meaningful learning strategy whereas more rejection responses were found for their counterparts. The TRDE scores of the two groups, however, were not significantly different. Unlike logical thinking ability or field dependence/independence, meaningful learning approach was found to have little effect on inducing cognitive conflict.

\section{Discussion}

\section{Quantifying Cognitive Conflict}

At first, we predicted that the students' responses to the discrepant event would fall into the eight response types as Chinn and Brewer (1998) proposed. However, two of them, ignoring and abeyance did not fit for our study although they had been both finely defined and had been encountered as responses in the test of the taxonomy. These inconsistencies might result from characteristics specific to the topic of density and/or the discrepant event used in our study.

First, ignoring and rejection merged into one response type. The only difference between ignoring and rejection, according to Chinn and Brewer (1998), is whether students try to explain why they cannot believe the discrepant event. This criterion made sense in their work because the anomalous data (i.e., discrepant events) were the results of rather complicated scientific experiments and there was room for students to point out certain kinds of problems regarding the experiments (e.g., insufficient data, inaccurate measurement, faulty methodology, etc.). In our study, however, the discrepant event was not only a simple experiment but also an example of clear and direct evidence against the initial explanation. This resulted in a situation that made it more difficult for students to specify their reasons for rejecting the discrepant event. In addition, consideration for the limitations imposed by the use of a paper-and-pencil test also led us to combine the two response types. Mason (2001) also pointed out this problem in studying eighth graders' responses to anomalous data concerning the meteor impact theory and/or the classic theory about the Giza pyramids. He suggested that the students who did not agree with the validity of the anomalous data without expressing any reason and did 
not discount their beliefs in the existing conceptions, might have ignored the data in the same way as had the students classified as the rejection type.

Uncertainty and abeyance also merged into one response type. Once again, the latter is different from the former in that students do not provide evident explanations for delaying their final decisions. In Chinn and Brewer's (1998) work, a wide range of explanations could be made because the initial theories allowed respondents to bring substantial background knowledge to bear. Moreover, the initial theories themselves are only "frontier theories" (Duschl, 1990) for which debates exist even among scientists. Therefore, students could hold out the possibility that the initial theory might be able to explain the anomalous data in the future. In our study, however, it is difficult to expect such responses because the "sink or float" problem is not so complex or obscure as to require later evidence and/or explanations.

Unlike ignoring and abeyance, belief decrease is a new response type in our study. Strictly speaking, however, belief decrease is not a distinctive response type as compared with the ones Chinn and Brewer (1998) proposed, because its characteristics are similar to belief change except for the extent of students' conviction toward abandoning their existing conceptions. As stated earlier, however, belief decrease responses indicated that students admitted the problems associated with their existing conceptions but they did not completely give up such conceptions. It is problematic to regard both response types as identical from the viewpoint of quantifying the degree of cognitive conflict. Thus, we separated belief decrease from belief change and treated it as an independent response type exclusively with intent to quantify cognitive conflict.

It was found that students had a particular conception regarding weight (or heaviness) from their responses to the discrepant event. The term "weight" was used with two different meanings; it was a kind of homonym. One was the concept of weight of a certain object possessing almost the same meaning as that used by scientists. The other was the concept of "natural heaviness" of the certain material; they regarded matter like iron or stone as heavy materials and matter like wood or plastic as light materials by nature. This latter concept is very similar, not perfect from the scientific point of view, to that of "density" although the students had not yet formally learned the concept of density. This early-stage concept of density, however, 
has two facets. Sometimes it helped students to realize that a problem existed with their current conceptions, which led them to abandon their previous beliefs. Twenty-five students changed their existing beliefs on the basis of this early-stage density concept, although there was still a little confusion about using the term "weight." Sometimes, on the contrary, it could be an obstacle to learning the scientific concept of density. Another 26 students responded to the discrepant event with reinterpretation, exclusion, or peripheral belief change on the basis of the same early-stage density concept. It is noteworthy that an early-stage concept of density functioned, at least for some students, as an important tool to maintain their existing undifferentiated weight-density conception.

It is very important to clarify the types of responses given by students with respect to discrepant events; such an action can help teachers expect and prepare for students' possible reactions to conceptual change instruction. From this point of view, the taxonomy Chinn and Brewer (1998) proposed is very useful. Although the settings of their study were rather different from those of practical classrooms (e.g., several different theories and several pieces of anomalous data), their taxonomy accurately anticipated most middle school students' response types.

The distribution of students' responses in this study was very different, however, from that reported by Chinn and Brewer (1998) (Table 1). Compared to those reported by Chinn and Brewer, the percentages of rejection (including ignoring), reinterpretation, and uncertainty (including abeyance) were relatively smaller, whereas the percentage of belief change was much higher in our study. A possible reason for such disparate differences might be associated with the characteristics of the respective topics used. Unlike our study, Chinn and Brewer selected frontier theories, possessing rival alternatives, as the initial theories and presented students with evidence from rather complicated and expert scientific experiments as discrepant events. There might be more room for students to raise questions regarding the validity of the discrepant events in those contexts because the topics chosen had inherent unsolved problems. Therefore, a greater frequency of responses such as rejection, reinterpretation, and uncertainty should not be unusual in their study. In addition, as Mason (2001) pointed out, the discrepant events that Chinn and Brewer used possessed a peculiar characteristic in which students had to rely 
only on the argumentative plausibility and the justifiability as they appeared in the given texts. In contrast, the discrepant event used in our study - a "sink or float" experiment - must be one of the most frequently experienced phenomena in students' everyday life. Thus, students could have pictured the discrepant event and/or related experience in their mind and could have judged the value of their existing conceptions with relative ease, which lead more students to abandon their existing conceptions.

\section{Cognitive Conflict and Conceptual Change}

The role of conflict in cognitive development and/or learning is a topic of ongoing debate (e.g., Cantor, 1983; Murray, 1983; Zimmerman \& Blom, 1983; see Limón, 2001, for a review in science education). Most Piagetian advocates (i.e., personal or radical constructivists; Geelan, 1997) hypothesize that cognitive conflict is a precondition for intellectual development. Other researchers, such as social learning theorists, have not considered cognitive conflict as crucial to learning (Bandura, 1977). Social learning theorists regard learning as a form of rule acquisition and emphasize other parameters of social experience like the clarity and consistency of modeled information (Zimmerman, 1977). Some science educators who emphasize the importance of social, environmental, and/or contextual aspects of conceptual change (e.g., social constructivists) also criticize the use of cognitive conflict as an instructional strategy. Their reason is that students tend to superficially patch up local inconsistencies without reaching the necessary conceptual change in situations of cognitive conflict (Vosniadou, 1999). The results of this study implied that both positions may have some validity. First, statistically significant correlations were found between the degrees of cognitive conflict and conceptual change. This result can be inferred to mean that cognitive conflict might be an important factor and should be considered in the process of concept learning. On the other hand, the correlation coefficient was rather low which means that cognitive conflict might not be as crucial in concept learning as Piagetian advocates expect. Thus, perhaps there is a strong possibility that cognitive conflict is only one of the important factors to be considered in concept learning rather than a necessary prerequisite for it. 
Logical thinking ability was found to be significantly correlated statistically with cognitive conflict. Students with high logical thinking ability aroused more cognitive conflict after experiencing the discrepant event than those with low ability. A possible interpretation of this result is that students with low logical thinking ability do not possess the capability necessary to appropriately evaluate the discrepant event. It is necessary for students to evaluate the validity of a discrepant event and the degree of inconsistency between such a discrepant event and their existing conceptions to initiate cognitive conflict (Limón, 2001). The students with low ability might fail to reach the expected threshold necessary to provoke conflict for the lack of reasoning skill. This interpretation is consistent with previous research. It was reported that students with higher logical thinking ability tended to reduce conflict on their own whereas those with lower ability sought information from other sources (Gorsky \& Finegold, 1994). Lawson and Thompson (1988) also reported that when a new theory that is not consistent with their existing one is presented, concrete-operational students tended to fail to reject the naive theory because they might lack the reasoning skill to internally evaluate the relative merits and demerits of their naive theory and the competing theory.

Field dependence/independence was also found to be significantly correlated with cognitive conflict. With respect to the discrepant event provided, more cognitive conflict was generated among field independent students than for field dependent ones. Witkin et al. (1977) indicated that field independence is the ability to disembed relevant information from an irrelevant background. Field independent students also tend to use better organizing and structuring strategies (Davis, 1991) and to be good at analytical problem solving (Gordon, 1998). The interpretation of this result agrees well with the previous research. Field independent students might be more capable of detecting the inconsistency between the discrepant event and their existing conceptions, and might approach the information presented in the discrepant event more analytically than field dependent students. Therefore, there is a greater possibility of engaging cognitive conflict among field independent students. 


\section{Implications for Teachers}

When teachers plan to teach the concept of density, they should pay close attention to students' preinstructional conceptions to eliminate potential obstacles to conceptual change. As stated in the discussion above, at least half of the seventh graders in this study (including those who were excluded from participating as subjects) were found to have an early-stage density concept even before they formally learned it in school. The problem, ironically, is that this early-stage density concept might lead some students to respond to discrepant events with rejection or reinterpretation while still others respond with belief change. Therefore, when introducing the concept of density, teachers should emphasize the differentiation between weight and density because the problem many students have is not that they do not understand the concept of density but that they cannot distinguish one concept from the other. In addition, the results concerning the influences of students' cognitive characteristics on cognitive conflict implied that intimate knowledge of students' cognitive characteristics is indispensable to teachers who are trying to overcome persistent misconceptions among their students.

\section{Further Research}

We defined and quantified, in this study, the degree of cognitive conflict induced by a discrepant event exclusively from a cognitive viewpoint. Like all operational definitions of theoretical concepts, however, the alternative definition for cognitive conflict developed here cannot respond perfectly to each and every situation because of the complexity of human learning. Discrepant events, as previously shown, play an important role in inducing cognitive conflict as well as initiating students' motivation to learn through the use of a learning cycle (Lawson, Abraham, \& Renner, 1989) or generative learning model (Osborne \& Freyberg, 1985). It was reported that students showed more curiosity and interest when the given phenomenon or information is not consistent with their expectations (e.g., Frick, 1992; Yarlas \& Gelman, 1998).

The interest stimulated by an inconsistent experience (i.e., discrepant events) could lead students to pay more attention to the learning 
material. In addition, evidence from previous research suggested that interest not only motivates students to learn but also influences comprehension and learning (see Schraw \& Lehman, 2001, for a review). Pintrich (1999) and Pintrich, Marx, and Boyle (1993) suggested that motivational constructs, such as mastery goal orientation, adoption of a constructivist belief about learning, higher levels of personal interest, self-efficacy, and personal control, should be potential mediators of the process of conceptual change. Hidi (1990) also suggested that the concept of interest should be recognized as an integral part of cognition and incorporated into expanded theories on the subject. Considering these suggestions, further research including the examination of the motivational role of conflict is needed to get a comprehensive understanding regarding the role of cognitive conflict in conceptual change.

The processes which comprise the phenomenon of learning, especially in practical classrooms, are very complicated because many interactions among students, teacher, and environments simultaneously occur. In this study, we purposely ruled out student(s)-student(s), teacher-student(s), and student(s)-environment interactions in order to isolate conditions as far as possible for all participants. Our decision for excluding the interactions might underestimate the interdependent relationships among those variables investigated in this study and the need for these interactions. The intervention of this study may be too short (i.e., the administration of both the TRDE and the CAI corresponds to about one class period of normal instruction). However, the content could be covered in one class period under the National Science Curriculum of Korea, and the result of a conceptual change instruction in our previous study indicated that the intervention of one class period was reasonably successful at least in learning the basic density concept (Noh et al., 1997). Further investigation may be needed to reveal the influence of intervention time on the relationship between cognitive conflict and conceptual change.

Considering that initial belief changes are not very stable, a further piece of research to test the longevity of the changed beliefs (e.g., administering a retention conception test) might reveal other aspects of the relationship between cognitive conflict and conceptual change. In order to understand the relationship between students' logical thinking ability and cognitive conflict, further research is also needed. Students who are above a certain threshold level in logical thinking ability 
may benefit from cognitive conflict, while those below the threshold level may not identify the conflict. Finally, considering the result that students' reasoning skill and cognitive style influenced the degree of cognitive conflict they experienced, further research is also needed to find out the most appropriate content and/or type of discrepant events to use; content/type of discrepant event(s) that is consistent with students' cognitive characteristics.

Acknowledgment - The work was supported by the Korea Research Foundation Grant (KRF-2001-037-CBoo40).

\section{References}

Adey, P., \& Shayer, M. (1988). Strategies for meta-learning in physics. Physics Education, 23(2), 97-104.

Bandura, A. (1977). Social learning theory. Englewood Cliffs, NJ: Prentice-Hall.

Berlyne, D. E. (1970). Children's reasoning and thinking. In P. Mussen (Ed.), Carmichael's manual of child psychology (pp. 939-981). New York:Wiley.

Borges, A. T., \& Gilbert, J. K. (1999). Mental models of electricity. International Journal of Science Education, 21(1), 95-117.

Cantor, G. N. (1983). Conflict, learning, and Piaget: Comments on Zimmerman and Blom's "Toward an empirical test of the role of cognitive conflict in learning." Developmental Review, 3, 39-53.

Cavallo, A. M. L. (1996). Meaningful learning, reasoning ability, and students' understanding and problem solving of topics in genetics. Journal of Research in Science Teaching, 33(6), 625-656.

Cavallo, A. M. L., \& Schafer, L. E. (1994). Relationships between students' meaningful learning orientation and their understanding of genetics topics. Journal of Research in Science Teaching, 31(4), 393-418.

Chambers, S. K., \& Andre, T. (1997). Gender, prior knowledge, interest, and experience in electricity and conceptual change text manipulations in learning about direct current. Journal of Research in Science Teaching, 34(2), 107-123.

Chan, C., Burtis, J., \& Bereiter, C. (1997). Knowledge building as a mediator of conflict in conceptual change. Cognition and Instruction, 15(1), 1-40.

Chinn, C. A., \& Brewer, W. F. (1993). The role of anomalous data in knowledge acquisition: A theoretical framework and implications for science instruction. Review of Educational Research, 63(1), 1-49.

Chinn, C. A., \& Brewer,W. F. (1998). An empirical test of a taxonomy of responses to anomalous data in science. Journal of Research in Science Teaching, 35(6), 623-654. 
Davis, J. K. (1991). Educational implications of field dependence-independence. In S. Wapner \& J. Demick (Eds.), Field dependence-independence: Cognitive style across the life span (pp. 149-175). Hillsdale, NJ: Erlbaum.

Donn, S. (1989, March). Epistemological issues in science education. Paper presented at the annual meeting of the National Association for Research in Science Teaching, San Francisco, CA.

Dreyfus, A., Jungwirth, E., \& Eliovitch, R. (1990). Applying the "cognitive conflict" strategy for conceptual change - some implications, difficulties, and problems. Science Education, 74(5), 555-569.

Driver, R. (1994). Making a sense of secondary science. London: Routledge.

Duff, A. (1997). A note on the reliability and validity of a 30-item version of Entwistle \& Tait's Revised Approaches to Studying Inventory. British Journal of Educational Psychology, 67(4), 529-539.

Duschl, R. A. (1990). Restructuring science education: The importance of theories and their development. New York: Teachers College Press.

Entwistle, N. J., \& Ramsden, P. (1983). Understanding student learning. New York: Nichols Publishing Company.

Entwistle, N. J., \& Tait, H. (1994). The Revised Approaches to Studying Inventory. Edinburgh, UK: University of Edinburgh, Center for Research on Learning and Instruction.

Frick, R. W. (1992). Interestingness. British Journal of Psychology, 83(1), 113-128.

Geelan, D. R. (1997). Epistemological anarchy and the many forms of constructivism. Science and Education, 6(1), 15-28.

Gordon, H. R. D. (1998, July). Identifying learning styles. Paper presented at the annual Summer Workshop for Beginning Vocational Education Teachers, Montgomery, West Virginia.

Gorsky, P., \& Finegold, M. (1994). The role of anomaly and of cognitive dissonance in restructuring students' concepts of force. Instructional Science, 22, 75-90.

Guzzetti, B. J., Snyder, T. E., Glass, G. V., \& Gamas, W. S. (1993). Promoting conceptual change in science: A comparative meta-analysis of instructional interventions from reading education and science education. Reading Research Quarterly, 28(2), 116-159.

Hewson, M. G. (1986). The acquisition of scientific knowledge: Analysis and representation of student conceptions concerning density. Science Education, $70(2), 159-170$.

Hewson, M. G. (1988). The ecological context of knowledge: Implications for learning science in developing countries. Journal of Curriculum Studies, 20(4), 317-326.

Hewson, M. G., \& Hewson, P. W. (1983). Effect of instruction using students' prior knowledge and conceptual change strategies on science learning. Journal of Research in Science Teaching, 20(8), 731-743.

Hidi, S. (1990). Interest and its contribution as a mental resource for learning. Review of Educational Research, 6o(4), 549-571. 
Kahle, J. B., \& Meece, J. (1994). Research on gender issues in the classroom. In D. L. Gabel (Ed.), Handbook of research on science teaching and learning (pp. 542-558). New York: Macmillan.

Klopfer, L. E., Champagne, A. B., \& Chaiklin, S. D. (1992). The ubiquitous quantities: Explorations that inform the design of instruction on the physical properties of matter. Science Education, 76(6), 597-614.

Lawson, A. E., \& Thompson, L. D. (1988). Formal reasoning ability and misconceptions concerning genetics and natural selection. Journal of Research in Science Teaching, 25(9), 733-746.

Lawson, A. E., Abraham, M. R., \& Renner, J. W. (1989). A theory of instruction: Using the learning cycle to teach science concepts and thinking skills (Monograph of the NARST, No 1). Cincinnati, OH: National Association for Research on Science Teaching.

Limón, M. (2001). On the cognitive conflict as an instructional strategy for conceptual change: A critical appraisal. Learning and Instruction, 11(4-5), 357-380.

Limón, M., \& Carretero, M. (1997). Conceptual change and anomalous data: A case study in the domain of natural sciences. European Journal of Psychology of Education, 12(2), 213-230.

Linn, M. C. (1986). Science. In R. Dillon \& R. J. Sternberg (Eds.), Cognition and instruction (pp. 155-204). New York: Academic Press.

Linn, M. C., \& Kyllonen, P. (1981). The field dependence-independence construct: Some, one or none. Journal of Educational Psychology, 73(2), 261-273.

Mason, L. (2001). Responses to anomalous data on controversial topics and theory change. Learning and Instruction, 11(6), 453-483.

Murray, F. B. (1983). Equilibration as cognitive conflict. Developmental Review, 3, 54-61.

Noh, T., Kang, S., Kim, H., Chae, W., \& Noh, S. (1997). Development and application of a conceptual change model for effective laboratory teaching. Journal of the Korean Association for Research in Science Education, 17, 179189 (Korean).

Osborne, R. J., \& Freyberg, P. (1985). Learning in science: The implications of children's science. Auckland, New Zealand: Heinemann Publisher.

Pintrich, P. R. (1999). Motivational beliefs as resources for and constraints on conceptual change. In W. Schnotz, S. Vosniadou, \& M. Carretero (Eds.), New perspectives on conceptual change (pp. 3-13). Oxford, UK: Elsevier Science Ltd.

Pintrich, P. R., Marx, R.W., \& Boyle, R. A. (1993). Beyond cold conceptual change: The role of motivational beliefs and classroom contextual factors in the process of conceptual change. Review of Educational Research, 63(2), 167-199.

Posner, G. J., Strike, K. A., Hewson, P. W., \& Gertzog, W. A. (1982). Accommodation of a scientific conception: Toward a theory of conceptual change. Science Education, 66(2), 211-227.

Rieck, W. (1994). Density: A discovery approach. Science Activities, 31(2), 19-23. 
Roadrangka, V., Yeany, R. H., \& Padilla, M. J. (1983, April). The construction and validation of Group Assessment of Logical Thinking (GALT). Paper presented at the annual meeting of the National Association for Research in Science Teaching, Dallas, TX.

Roald, I., \& Mikalsen, O. (2000). What are the Earth and the heavenly bodies like? A study of objectual conceptions among Norwegian deaf and hearing pupils. International Journal of Science Education, 22(4), 337-355.

Rowell, J. A., \& Dawson, C. J. (1977). Teaching about floating and sinking: An attempt to link cognitive psychology with classroom practice. Science Education, 61(2), 245-253.

Schraw, G., \& Lehman, S. (2001). Situational interest: A review of the literature and directions for future research. Educational Psychology Review, 13(1), 23-52.

Scott, P. H., Asoko, H. M., \& Driver, R. H. (1992). Teaching for conceptual change: A review of strategies. In R. Duit, F. Goldberg, \& H. Niedderer (Eds.), Research in physics learning: Theoretical issues and empirical studies (pp. 310-329). Kiel, Germany: Institut für die Pädagogik der Naturwissenschaften an der Universität Kiel.

Shepardson, D. P., \& Moje, E. B. (1999). The role of anomalous data in restructuring fourth graders' frameworks for understanding electric circuits. International Journal of Science Education, 21(1), 77-94.

Shepherd,D. L.,\& Renner, J.W. (1982). Student understandings and misunderstandings of states of matter and density changes. School Science and Mathematics, 82(8), 650-665.

Smedslund, J. (1961). The acquisition of conservation of substance and weight in children. Scandinavian Journal of Psychology, 2, 156-16o. Smith, C., Carey, S., \& Wiser, M. (1985). On differentiation: A case study of the development of the concepts of size, weight, and density. Cognition, 21(3), 177- 237.

Smith, C., Snir, J., \& Grosslight, L. (1992). Using conceptual models to facilitate conceptual change: The case of weight-density differentiation. Cognition and Instruction, 9(3), 221-283.

Stavy, R., \& Berkovitz, B. (1980). Cognitive conflict as a basis for teaching quantitative aspects of the concept of temperature. Science Education, 64, 679-692.

Strike, K. A., \& Posner, G. J. (1992). A revisionist theory of conceptual change. In R. Duschl \& R. Hamilton (Eds.), Philosophy of science, cognitive psychology, and educational theory and practice (pp. 147-176). Albany, NY: State University of New York Press.

Teixeira, F. M. (2000). What happens to the food we eat? Children's conceptions of the structure and function of the digestive system. International Journal of Science Education, 22(5), 507-520.

Tirosh, D., Stavy, R., \& Cohen, S. (1998). Cognitive conflict and intuitive rules. International Journal of Science Education, 20(10), 1257-1269. 
Tsai, C.-C. (2000). Enhancing science instruction: The use of 'conflict maps.' International Journal of Science Education, 22(3), 285-302.

Tytler, R. (2000). A comparison of year 1 and year 6 students' conceptions of evaporation and condensation: Dimensions of conceptual progression. International Journal of Science Education, 22(5), 447-467.

Vandenplas-Holper, C. (1996). Intraindividual and interindividual cognitive conflict, related variables and relations with cognitive development. Swiss Journal of Psychology, 55(2/3), 161-175.

Voska, K. W., \& Heikkinen, H. W. (2000). Identification and analysis of student conceptions used to solve chemical equilibrium problems. Journal of Research in Science Teaching, 37(1), 160-176.

Vosniadou, S. (1999). Conceptual change research: State of the art and future directions. In W. Schnotz, S. Vosniadou, \& M. Carretero (Eds.), New perspectives on conceptual change (pp. 3-13). Oxford, UK: Elsevier Science Ltd.

Witkin, H. A., Moore, C. A., Goodenough, D. R., \& Cos, P. W. (1977). Field dependent and field independent cognitive styles and their educational implications. Reviews of Educational Research, 47, 1-64.

Yarlas, A. S., \& Gelman, R. (1998, April). Learning as a predictor of situational interest. Paper presented at the annual meeting of the American Educational Research Association, San Diego, CA.

Zimmerman, B. J. (1977). Modeling. In H. Hom\& P. Robinson (Eds.), Psychological processes in early education (pp. 37-70). New York: Academic Press.

Zimmerman, B. J., \& Blom, D. E. (1983). Toward an empirical test of the role of cognitive conflict in learning. Developmental Review, 3, 18-38. 